CLINICAL STUDY

\title{
Hypothalamic-pituitary-adrenal axis activity in adults who were prenatally exposed to the Dutch famine
}

\author{
Susanne R de Rooij ${ }^{1}$, Rebecca C Painter ${ }^{1}$, David I W Phillips ${ }^{4}$, Clive Osmond ${ }^{4}$, Robert P J Michels ${ }^{2}$, \\ Patrick M M Bossuyt ${ }^{1}$, Otto P Bleker ${ }^{3}$ and Tessa J Roseboom ${ }^{1}$ \\ Departments of ${ }^{1}$ Clinical Epidemiology and Biostatistics, ${ }^{2}$ Internal Medicine and ${ }^{3}$ Obstetrics and Gynaecology, Academic Medical Centre, University \\ of Amsterdam, 1100DD Amsterdam, The Netherlands and ${ }^{4}$ MRC Epidemiology Resource Centre at the University of Southampton, Southampton, \\ SO16 6YD, UK \\ (Correspondence should be addressed to S R de Rooij; Email: s.r.derooij@amc.uva.nl)
}

\begin{abstract}
Objective: The hypothalamic-pituitary-adrenal (HPA) axis has been proposed to be susceptible to fetal programming, the process by which an adverse fetal environment elicits permanent physiological and metabolic alterations predisposing to disease in later life. It is hypothesized that fetal exposure to poor circumstances alters the set point of the HPA axis, leading to increased HPA axis activity and subsequent increased cortisol concentrations. In this study, we tested the hypothesis that prenatal exposure to famine during different periods of gestation is associated with increased activity of the HPA axis.

Design and methods: We assessed plasma cortisol concentrations after a dexamethasone suppression and an $\mathrm{ACTH}_{1-24}$-stimulation test in a group of 98 men and women randomly sampled from the Dutch famine birth cohort. Cohort members were born as term singletons around the 1944-1945 Dutch famine.

Results: Cortisol profiles after dexamethasone suppression and $\mathrm{ACTH}_{1-24}$ stimulation were similar for participants exposed to famine during late, mid- or early gestation $(P=0.78)$. Cortisol concentrations after dexamethasone suppression test did not differ between those exposed and those unexposed to famine in utero (mean difference $-2 \%$ (95\% confidence interval (CI) -27 to 23)). Neither peak cortisol concentration $(20 \mathrm{nmol} / \mathrm{l}(95 \% \mathrm{CI}-27$ to 66$))$, cortisol increment ( $-5 \mathrm{nmol} / \mathrm{l}(95 \% \mathrm{CI}-56$ to 47$))$ or cortisol area under the curve post-ACTH ${ }_{1-24}$ injection (4\% (95\% CI -4 to 12)) differed between exposed and unexposed participants.

Conclusions: Prenatal famine exposure does not seem to affect HPA axis activity at adult age, at least not at the adrenal level. This does not exclude altered HPA axis activity at the levels of the hippocampus and hypothalamus.
\end{abstract}

European Journal of Endocrinology 155 153-160

\section{Introduction}

The fetal origins hypothesis states that an adverse fetal environment may elicit permanent physiological and metabolic alterations predisposing to disease in later life, a process called fetal programming (1). The hypothalamic-pituitary-adrenal (HPA) axis has been proposed to be susceptible to fetal programming. Prenatal undernutrition may program the HPA axis by permanently altering the set point of the HPA axis in utero, leading to increased activity and subsequent increased concentrations of cortisol that predispose to cardiovascular disease and type 2 diabetes (2-4). In utero resetting of the HPA axis may thus be an important link between early life events and these chronic adult diseases.

Animal studies have established that prenatal nutrition can affect the functioning of the HPA axis in adult life. The newborn progeny of rats exposed to a low protein diet during late gestation, show increased HPA axis activity as indicated by elevated levels of basal plasma corticotropin (ACTH) and corticosterone (5). Modest as well as severe prenatal undernutrition during early and late gestation in sheep produces increased post-natal activity of the HPA axis after a corticotropinreleasing hormone plus arginine vasopressin challenge $(6,7)$. Studies in guinea pigs that were undernourished during a short period in late gestation have shown clear sex-specific alterations in HPA axis activity at adult age (8). Basal ACTH and cortisol responses are reduced in male guinea pigs, while in females basal ACTH responses remain unchanged and cortisol responses are elevated compared with normally fed animals.

Fetal programming of the HPA axis has been identified in humans who were small at birth. Small size at birth is considered to reflect a poor fetal environment. Low birth weight was found to be associated with elevated fasting plasma cortisol concentrations in a variety of populations of men and women $(9,10)$. People who were small at birth also show 
increased responsiveness to dexamethasone suppression and increased responsiveness to corticotropin releasing hormone and ACTH stimulation, although some studies failed to find evidence for these associations (11-14).

In previous studies, we have shown that prenatal exposure to undernutrition during different periods of gestation in the Dutch famine was associated with a range of risk factors for, as well as an increased prevalence of, coronary heart disease (CHD) and type 2 diabetes at adult age (15-21). The Dutch famine was a period of 5 months of severe undernutrition at the end of World War II. Although it was a historical disaster, it provides us with the opportunity to study the long-term health effects of undernutrition during different periods in pregnancy. Programming of the HPA axis may explain the association between famine exposure in utero and the increased risk of CHD and type 2 diabetes in later life. In a new study, we tested the hypothesis that prenatal exposure to famine during late, mid and/or early gestation is associated with increased activity of the HPA axis.

\section{Materials and methods}

\section{The Dutch famine birth cohort}

The Dutch famine birth cohort members were born as term singletons between 1 November 1943 and 28 February 1947 at the Wilhelmina Gasthuis in Amsterdam, The Netherlands. The selection procedure is described in detail elsewhere (15). At age 58, 1423 of the 2414 original cohort members $(58 \%)$ were still alive, living in The Netherlands and their address was known to the investigators. These people were eligible for our study.

\section{Exposure to famine}

We defined the famine period according to the official daily food-rations for the general population older than 21 years. The official rations accurately reflect the variation over time in the total amount of food available in the west of the Netherlands (22). We considered fetuses to have been exposed to famine in utero if the average daily rations for those older than 21 years during any 13-week period of gestation were less than 1000 calories. According to this definition, people born between 7 January 1945 and 8 December 1945 were considered to be exposed to famine in utero. We defined periods of 16 weeks each to differentiate between those who were exposed to famine in late gestation (born between 7 January 1945 and 28 April 1945), in mid gestation (born between 29 April and 18 August 1945) and in early gestation (born between 19 August and 8 December 1945). People born before 7 January 1945 and conceived and born after 8 December 1945 were considered to be unexposed to famine in utero.

\section{Participants}

All 1423 eligible Dutch famine birth cohort members were invited to attend the clinic for a data-collection protocol, which included a $75 \mathrm{~g}$ oral glucose tolerance test (23). We were able to complete this test for 699 of the 810 study participants. Based on the results of the oral glucose tolerance test, we selected 100 normoglycaemic men and women for participation in a dexamethasone suppression and an $\mathrm{ACTH}_{1-24}$-stimulation test using the same protocol as described by Reynolds et al. (13). For this purpose, 10 men and 10 women were randomly selected from each of the following study groups: people born before the famine, people exposed to famine in late gestation, people exposed in mid gestation, people exposed in early gestation and people conceived after the famine. We defined normoglycemia as 120-min plasma glucose concentrations below $7.8 \mathrm{mmol} / \mathrm{l}$ in accordance with the definition in our previous study and the 1999 World Health Organisation (WHO) recommendations $(15,24)$. Participants taking oral glucocorticoids were excluded from selection. The local Medical Ethics Committee approved the study, which was carried out in accordance with the Declaration of Helsinki. Written informed consent was obtained from all participants.

\section{Dexamethasone suppression and ACTH $_{1-24}$-stimulation test}

The participants were asked to take $0.25 \mathrm{mg}$ dexamethasone at $2200 \mathrm{~h}$ and to fast overnight. The following morning they attended the clinic where a cannula was placed in the antecubital vein. After a 30-min period of resting, a baseline blood sample was taken and $1 \mu \mathrm{g} \mathrm{ACTH}_{1-24}$ (Tetracosactid, Synacthen, Novartis Pharma, Arnhem, The Netherlands) was injected intravenously as a bolus. Venous blood samples were taken 20, 30, 40 and $60 \mathrm{~min}$ after injection of $\mathrm{ACTH}_{1-24}$. Plasma cortisol concentrations were measured by enzyme immunoassay (Diagnostic Products Corporation, Los Angeles, CA, USA) with a detection limit of $50 \mathrm{nmol} / \mathrm{l}$. Cortisol concentrations in the baseline sample were used to indicate dexamethasone suppression. We used low doses of dexamethasone $(0.25 \mathrm{mg})$ and $\mathrm{ACTH}_{1-24}(1 \mu \mathrm{g})$ instead of conventional doses (e.g. $1 \mathrm{mg}$ dexamethasone and $250 \mu \mathrm{g} \mathrm{ACTH}_{1-24}$ ) to be able to detect the subtle alterations in cortisol responses after suppression and stimulation to be expected in healthy participants. Conventional doses would induce maximal effects in all participants and minimise the possibility of detecting differences between participants exposed and unexposed to famine in utero.

\section{Interview and anthropometric measurements}

We measured height with a portable stadiometer and weight with a portable Tefal scale. We asked participants 
about their use of medication. All other data used in this study were collected on the day the oral glucose tolerance test was performed (23). Waist circumference was measured with a flexible tape measure. Information on socioeconomic status, medical history and lifestyle was retrieved from a standardized interview. Current socioeconomic status was coded according to ISEI-92, a numeric scale based on the person's, or their partner's occupation, whichever status is highest (25).

\section{Clinical measurements}

Plasma glucose concentrations obtained during the earlier performed oral glucose tolerance test (25) were measured by a standardised enzymatic photometric assay on a Modular P analyser (Roche). Plasma insulin concentrations were measured by an immuno-luminometric assay on an Immulite 2000 analyser (Diagnostic Product Corporation). Blood was drawn for analysis of low- and high-density lipoprotein cholesterol. Blood pressure was measured in duplicate on two occasions (morning and afternoon) using an automated device (Omron 705CP/IT, Omron Healthcare UK, West Sussex, UK). Mean systolic and diastolic blood pressure was calculated using all available measurements. Standard 12-lead electrocardiograms (ECG) were taken from the participants. The presence of $\mathrm{CHD}$ was defined as the presence of one or more of the following: angina pectoris according to the Rose/WHO questionnaire; Q-waves on the ECG (Minnesota codes 1-1 or 1-2) or a history of coronary revascularisation (angioplasty or bypass surgery). We defined the metabolic syndrome according to the recommendations of the National Cholesterol Education Program (NCEP), modified in 2004 in accordance with the American Diabetes Association (ADA) $(26,27)$.

\section{Statistical methods}

We took the highest concentration of cortisol in the line of 20,30, 40 and 60-min cortisol concentrations of each individual as the peak cortisol level. We subtracted the baseline cortisol concentration from the peak cortisol concentration to obtain cortisol increment. We calculated the area under the curve (AUC) for cortisol from 0 to $60 \mathrm{~min}$ post- $\mathrm{ACTH}_{1-24}$ following the trapezoidal rule (base $\times$ average height under cortisol curve). To obtain normality in case of a skewed distribution, we applied logarithmic transformations to the variables: body mass index (BMI), socio-economic status, 2-h insulin, systolic blood pressure, diastolic blood pressure, high density lipoprotein (HDL) cholesterol, post-dexamethasone cortisol and AUC cortisol. Spearman's rank correlations were calculated between maternal, birth, adult and cortisol outcomes. Linear and logistic regression analyses were used to detect possible differences in cortisol outcomes between the groups of people exposed and unexposed to famine in utero. Effect sizes and confidence intervals (CI) are given as percentage difference between groups for logarithmically transformed outcome variables.

We used a general linear mixed model analysis to investigate differences between the exposed and unexposed groups in the course of cortisol concentrations over time after injection of $\mathrm{ACTH}_{1-24}$. In all our regression analyses we adjusted for gender and BMI. Additional adjustment was performed for a range of variables including maternal and birth characteristics, smoking, socioeconomic status, treatment with estrogen, treatment with anti-depressive medication and use of inhaled corticosteroid medication. We considered differences to be statistically significant if $P$-values were smaller than 0.05 .

\section{Results}

Three people who were exposed to famine during early gestation were unable to participate. Inadvertently, in the group of participants born before the famine, one person too many was included. The group of 98 participants with dexamethasone suppression/ACTH ${ }_{1-24}$-stimulation tests consisted of 47 men and 51 women with a mean age of 58 years (s.D. 1 year), of which 57 (58\%) had been exposed to famine during gestation.

Table 1 shows that mothers of participants exposed to famine in early gestation were younger and gained more weight during the third trimester of pregnancy compared with mothers of unexposed participants. Mothers exposed in mid gestation also gained more weight, but weighed less at the end of pregnancy. Mothers exposed in late gestation gained no weight and weighed less at the end of pregnancy. Babies exposed to famine in mid gestation were smaller at birth compared with unexposed babies.

Table 2 shows that at age 58, those exposed to famine in early gestation had a lower socioeconomic status compared with those unexposed. They had higher 2-h glucose and 2-h insulin concentrations compared with unexposed participants. The 2 -h insulin concentrations were also higher for those exposed to famine during mid gestation.

\section{Cortisol concentrations and maternal and birth characteristics}

Table 3 shows correlations between maternal, birth and adult characteristics and cortisol outcomes. Post-dexamethasone and peak cortisol concentrations post$\mathrm{ACTH}_{1-24}$ injection were higher if the mother was older at delivery. With every year increase in maternal age, post-dexamethasone concentrations in the offspring increased by $2 \%(95 \% \mathrm{CI} 0-4)$ and post-ACTH ${ }_{1-24}$ peak cortisol concentrations increased by $4 \mathrm{nmol} / \mathrm{l}$ (95\% CI 0-7 nmol/l). Plasma cortisol concentrations after dexamethasone suppression were lower in those with low 
Table 1 General, maternal and birth characteristics according to timing of prenatal exposure to the Dutch famine. Results are means and S.D., except when indicated differently.

\begin{tabular}{|c|c|c|c|c|c|c|c|}
\hline & \multicolumn{7}{|c|}{ Exposure to famine } \\
\hline & $\begin{array}{l}\text { Born } \\
\text { before }\end{array}$ & $\begin{array}{l}\text { In late } \\
\text { gestation }\end{array}$ & $\begin{array}{l}\text { In mid } \\
\text { gestation }\end{array}$ & $\begin{array}{l}\text { In early } \\
\text { gestation }\end{array}$ & $\begin{array}{l}\text { Conceived } \\
\text { after }\end{array}$ & All (S.D.) & $n$ \\
\hline$n$ & 21 & 20 & 20 & 17 & 20 & & 98 \\
\hline \multicolumn{8}{|l|}{ General characteristics } \\
\hline Proportion of men & 0.48 & 0.50 & 0.50 & 0.41 & 0.50 & 0.48 & 98 \\
\hline Age & 58.9 & 58.4 & 58.0 & 57.8 & 57.3 & $58.1(0.7)$ & 98 \\
\hline \multicolumn{8}{|l|}{ Maternal characteristics } \\
\hline Age at delivery (years) & 30 & 32 & 29 & $25^{*}$ & 29 & $26(6)$ & 98 \\
\hline Weight gain 3rd trimester $(\mathrm{kg})$ & 1.6 & $0.0^{*}$ & $4.8^{\star}$ & $5.7^{\star}$ & 3.2 & $2.8(3.2)$ & 66 \\
\hline Weight at last antenatal visit $(\mathrm{kg})$ & 67.7 & $62.9^{*}$ & $63.8^{\star}$ & 68.9 & 70.2 & $66.7(8.2)$ & 88 \\
\hline \multicolumn{8}{|l|}{ Birth outcomes } \\
\hline Gestational age (days) & 285 & 283 & 285 & 290 & 288 & $286(11)$ & 84 \\
\hline Birth weight $(\mathrm{g})$ & 3318 & 3323 & $3086^{*}$ & 3464 & 3727 & $3380(471)$ & 98 \\
\hline
\end{tabular}

*Statistically significant difference $(P<0.05)$ compared with people unexposed to famine in utero.

birth weight. Post-dexamethasone concentrations decreased by $23 \%$ (95\% CI 7-39) per kilogram decrease in birth weight. Analysis of men and women separately showed that the association between low birth weight and low post-dexamethasone cortisol concentrations was statistically significant in women only $(36 \%$ decrease per kilogram decrease in birth weight $(95 \%$ CI $5-57)$ vs $9 \%$ decrease in men $(95 \% \mathrm{CI}-22-32))$.

\section{Cortisol concentrations and adult characteristics}

Men had higher cortisol concentrations after dexamethasone suppression (47\% (95\% CI 18-82)) and a lower cortisol increment after $\mathrm{ACTH}_{1-24}$ injection
$(-75 \mathrm{nmol} / \mathrm{l}(95 \% \mathrm{CI}-125$ to -25$))$ compared with women (see also Table 3). Peak cortisol concentrations and cortisol AUC post-ACTH ${ }_{1-24}$ injection were higher with higher 2-h glucose concentrations. Peak cortisol concentrations rose by $25 \mathrm{nmol} / \mathrm{l}(95 \% \mathrm{CI} 3-47)$ and cortisol AUC by $4 \%(95 \%$ CI $0-8)$ per $\mathrm{mmol} / \mathrm{l}$ increase in 2 -h glucose concentrations. Cortisol increment post$\mathrm{ACTH}_{1-24}$ injection was higher with higher 2-h insulin concentrations. Cortisol increment increased by $0.23 \mathrm{nmol} / \mathrm{l}$ per $\mathrm{pmol} / \mathrm{l}$ (95\% CI $0.08-0.38)$ increase in 2-h insulin concentrations.

Repeated measures analyses of the cortisol profiles showed that there were positive associations between the cortisol profile and waist:hip ratio $(P<0.01), 2$-h glucose $(P=0.03)$ and 2-h insulin concentrations, $(P=0.04)$

Table 2 Adult characteristics according to timing of prenatal exposure to the Dutch famine. Results are means and S.D., except when indicated differently.

\begin{tabular}{|c|c|c|c|c|c|c|}
\hline & \multicolumn{6}{|c|}{ Exposure to famine } \\
\hline & $\begin{array}{l}\text { Born } \\
\text { before }\end{array}$ & $\begin{array}{l}\text { In late } \\
\text { gestation }\end{array}$ & $\begin{array}{l}\text { In mid } \\
\text { gestation }\end{array}$ & $\begin{array}{l}\text { In early } \\
\text { gestation }\end{array}$ & $\begin{array}{l}\text { Conceived } \\
\text { after }\end{array}$ & All (S.D.) \\
\hline$n$ & 21 & 20 & 20 & 17 & 20 & 98 \\
\hline Proportion of current smokers & 0.10 & 0.15 & 0.15 & 0.24 & 0.15 & 0.15 \\
\hline Current socio-economic status\# & 51 & 52 & 46 & $40^{*}$ & 49 & 47 (1.3) \\
\hline Body mass index (BMI) $\left(\mathrm{kg} / \mathrm{m}^{2}\right) \#$ & 26.0 & 27.3 & 27.0 & 27.9 & 27.7 & $27.2(1.1)$ \\
\hline Waist:hip ratio & 91.1 & 91.9 & 91.5 & 93.1 & 90.0 & $91.5(7.8)$ \\
\hline $\begin{array}{l}\text { Systolic blood pressure } \\
\text { (mmHg)\# }\end{array}$ & 135 & 132 & 139 & 132 & 132 & $134(1.2)$ \\
\hline $\begin{array}{l}\text { Diastolic blood pressure } \\
\quad(\mathrm{mmHg})\end{array}$ & 80 & 78 & 84 & 82 & 82 & $81(11)$ \\
\hline Total cholesterol (mmol/l) & 5.8 & 6.1 & 6.1 & 5.8 & 5.9 & $5.9(1.0)$ \\
\hline HDL cholesterol (mmol//)\# & 1.54 & 1.43 & 1.41 & 1.50 & 1.37 & $1.45(1.3)$ \\
\hline 2-h glucose $(\mathrm{mmol} / \mathrm{l}) \#$ & 5.3 & 5.2 & 5.6 & $6.1^{* *}$ & 5.1 & $5.4(1.2)$ \\
\hline 2-h insulin (pmol/l)\# & 167 & 197 & $256^{\star *}$ & $294^{\star *}$ & 187 & $213(1.2)$ \\
\hline $\begin{array}{l}\mathrm{CHD} \\
\text { prevalence }\end{array}$ & 0.05 & 0.00 & 0.10 & 0.13 & 0.05 & 0.06 \\
\hline $\begin{array}{l}\text { Metabolic syndrome } \\
\text { prevalence } \dagger\end{array}$ & 0.24 & 0.15 & 0.45 & 0.18 & 0.25 & 0.26 \\
\hline
\end{tabular}

$\mathrm{CHD}$, coronary heart disease; HDL cholesterol, high density lipoprotein cholesterol; \#Geometric means and S.D.; *statistically significant difference $(P<0.05)$ compared with people unexposed to famine in utero; ${ }^{* *}$ statistically significant difference $(P<0.05$, adjusted for gender and BMI) compared with people unexposed to famine in utero. †According to the recommendations of the NCEP, modified in 2004 in accordance with the ADA (26, 27). 
Table 3 Associations between maternal, birth and adult characteristics and plasma cortisol concentrations.

\begin{tabular}{|c|c|c|c|c|c|c|}
\hline & Maternal age & Birth weight & $\begin{array}{l}\text { Gender }(\operatorname{men}=1, \\
\text { women }=2)\end{array}$ & BMI & 2-h glucose & 2-h insulin \\
\hline Post-dexamethasone cortisol & 0.15 & $0.23^{*}$ & $-0.34^{*}$ & -0.18 & -0.03 & $-0.22^{*}$ \\
\hline Peak cortisol post-ACTH & $0.23^{*}$ & 0.05 & 0.08 & -0.12 & $0.23^{*}$ & 0.04 \\
\hline $\begin{array}{l}\text { Cortisol increment } \\
\text { post-ACTH }\end{array}$ & 0.00 & -0.07 & $0.36^{*}$ & 0.18 & $0.28^{*}$ & $0.36^{*}$ \\
\hline $\begin{array}{l}\text { Cortisol area under curve } \\
\text { (AUC) post-ACTH }\end{array}$ & 0.18 & 0.17 & -0.05 & -0.12 & $0.23^{*}$ & 0.08 \\
\hline
\end{tabular}

Spearman's rank correlations.

* Statistically significant correlation $(P<0.05)$.

and the prevalence of the metabolic syndrome according to the recommendations of the NCEP $(P=0.03)$. Gender, BMI, age, lifestyle variables (smoking, alcohol), socioeconomic status and other clinical outcomes (systolic and diastolic blood pressure, total and HDL cholesterol and the prevalence of CHD) were not associated with the cortisol profile.

\section{Cortisol concentrations and prenatal famine exposure}

Cortisol profiles after suppression with dexamethasone and stimulation with $\mathrm{ACTH}_{1-24}$ for participants exposed to famine during late, mid or early gestation did not significantly differ from each other $(P=0.78)$ and were, therefore, grouped together for comparison with participants unexposed to famine in utero. The cortisol profiles after suppression with dexamethasone and stimulation with $\mathrm{ACTH}_{1-24}$ are shown in Figure 1 . Table 4 shows that cortisol concentrations after suppression with dexamethasone did not differ between those exposed and unexposed to famine in utero (mean difference $-2 \%$ (95\% CI -27 to 23)). Peak cortisol concentrations after injection with $\mathrm{ACTH}_{1-24}$ did not differ between prenatally famine exposed and unexposed $(20 \mathrm{nmol} / \mathrm{l}$ (95\% CI -27 to 66)) subjects. There were also no differences between the exposed and unexposed groups in cortisol increment post-ACTH ${ }_{1-24}(-5 \mathrm{nmol} / \mathrm{l}(95 \% \mathrm{CI}-56$ to $47)$ and cortisol AUC post-ACTH ${ }_{1-24}(4 \%$ (95\% CI -4 to 12)). Repeated measure analysis of the cortisol profiles showed that profiles of exposed and unexposed participants did not significantly differ from each other $(P=0.62)$. There was no interaction between sex and famine exposure $(P=0.94)$. Adjusting for maternal age, maternal weight gain, weight at the last antenatal visit, birth weight, smoking, socioeconomic status, treatment with estrogen, treatment with anti-depressive medication, and use of inhaled corticosteroid medication also did not alter the results.

\section{Discussion}

In the present study, we aimed to investigate whether prenatal exposure to famine is associated with increased activity of the HPA axis at age 58. We performed a dexamethasone suppression and an $\mathrm{ACTH}_{1-24}$-stimulation test, but found no differences in suppressed and stimulated cortisol concentrations between participants exposed and unexposed to famine in utero. These results suggest that the prenatal famine exposure does not program HPA axis activity, at least not at the adrenal level.

This study is a unique population-based study of men and women recruited from the original Dutch famine birth cohort still living in The Netherlands (15). The famine had a sudden beginning and end, and lasted for 5 months. This enables us to study the consequences of undernutrition during different stages of gestation. Although we found dexamethasone suppressed and $\mathrm{ACTH}_{1-24}$-stimulated cortisol concentrations in those prenatally exposed to famine in late, mid or early gestation to be similar to cortisol concentrations of those unexposed, we think it is too early to conclude that famine exposure in utero does not affect functioning of the HPA axis at all. There are some methodological drawbacks and issues that have to be taken into account.

Our study sample was relatively small and the considerable fluctuations in cortisol concentrations make it difficult to detect differences between groups. Also, participants were sampled from a normoglycaemic group. HPA programming by famine exposure may be more pronounced among those with impaired glucose tolerance and prenatal famine related differences in normoglycaemic participants might be too subtle to detect. With a significance level of $\alpha=0.05$, our study had $80 \%$ power to detect a minimal difference of 1 s.D. (about $100 \mathrm{nmol} / \mathrm{l}$ ) in peak cortisol level between participants unexposed to famine and participants exposed to famine in late, mid or early gestation.

Another issue concerns the fact that the dexamethasone suppression/ACTH ${ }_{1-24}$ activation test primarily acts at the adrenal level of the HPA axis, while higher levels of the HPA axis remain mostly unmeasured. The results of the present study suggest that prenatal famine exposure does not affect functioning of the HPA axis at the adrenal level, but it may affect functioning at a higher level. Experiments in which rats were pre-or perinatally undernourished showed physiological and functional changes at the levels of the hippocampus 


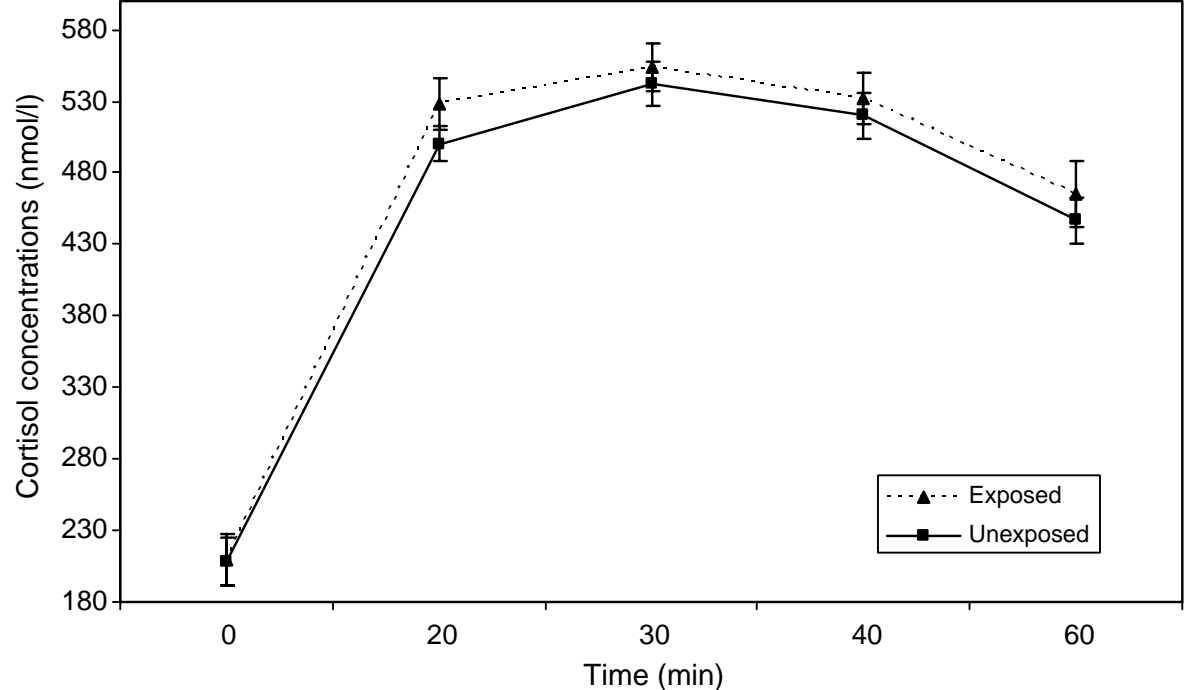

Figure 1 Cortisol profiles plotted as means ( \pm S.E.M.) after dexamethasone suppression (0) and $\mathrm{ACTH}_{1-24}$-stimulation (from 0 to $60 \mathrm{~min}$ ) for participants exposed and unexposed to famine in utero. $P=0.62$ for difference between the exposed and the unexposed group based on regression analysis, adjusted for gender and BMI. and hypothalamus $(5,28)$. Higher levels of the HPA axis can be tested by means of psychological stressors (29). We are currently investigating whether psychological stress leads to different HPA axis responses in humans exposed to famine in utero.

A final issue concerns the impact of increasing age. Various cohort studies have shown associations between low birth weight and cortisol concentrations across different age groups, implying there is no effect of age on the fetal programming of the HPA axis (10). Evidence from animal studies, however, seems to dispute this. Programming of the HPA axis by prenatal exposure to glucocorticoids was shown to be dependent on increasing age in studies of male guinea pigs $(30,31)$. Glucocorticoids-exposed 80-day-old guinea pigs showed a reduction in basal and activated pituitary-adrenal function compared with unexposed animals, while this effect was no longer observed at the age of 150 days. Programming effects on the activity of the HPA axis were still present, but persisted only at the level of the hippocampus. These age-dependent effects on the HPA axis are possibly modulated by changes in mineralcorticoid receptor levels. Effects of prenatal famine exposure on HPA axis activity may also have changed with increasing age. Unfortunately, we were not able to test the possible effects of increasing age, because all participants are of about the same age.

We found elevated dexamethasone suppressed and $\mathrm{ACTH}_{1-24}$-stimulated cortisol concentrations in participants born to mothers who were older at delivery. This result agrees with the result of a study that investigated HPA axis function in a cohort of children born in Jamaica (32). Some studies have shown associations between HPA axis responsiveness to $\mathrm{ACTH}_{1-24}$ stimulation and low birth weight $(13,14)$. We found no evidence for such an association in our study, but we found that low birth weight was associated with lower cortisol concentrations following dexamethasone suppression, although in women only. While most studies report that low birth weight is linked with high morning cortisol concentrations which are suppressed normally following dexamethasone $(10,13,14)$, associations

Table 4 Plasma cortisol concentrations according to timing of prenatal exposure to the Dutch famine. Results are means and s.D., except when indicated differently.

\begin{tabular}{|c|c|c|c|c|c|c|c|}
\hline & \multicolumn{7}{|c|}{ Exposure to famine } \\
\hline & $\begin{array}{l}\text { Born } \\
\text { before }\end{array}$ & $\begin{array}{l}\text { In late } \\
\text { gestation }\end{array}$ & $\begin{array}{l}\text { In mid } \\
\text { gestation }\end{array}$ & $\begin{array}{l}\text { In early } \\
\text { gestation }\end{array}$ & $\begin{array}{l}\text { Conceived } \\
\text { after }\end{array}$ & All (S.D.) & $n$ \\
\hline $\begin{array}{l}\text { Post-dexamethasone cortisol } \\
(\mathrm{nmol} / \mathrm{l}) \#\end{array}$ & 177 & 205 & 166 & 158 & 186 & $178(1.8)$ & 96 \\
\hline $\begin{array}{l}\text { Peak cortisol post-ACTH } \\
\text { (nmol/l) }\end{array}$ & 608 & 600 & 590 & 584 & 539 & $584(110)$ & 89 \\
\hline $\begin{array}{l}\text { Cortisol increment post-ACTH } \\
(\mathrm{nmol} / \mathrm{l})\end{array}$ & 402 & 351 & 389 & 399 & 358 & $380(123)$ & 87 \\
\hline $\begin{array}{l}\text { Cortisol AUC post-ACTH } \\
\text { (nmol/l/min)\# }\end{array}$ & 27623 & 27496 & 27101 & 27581 & 26008 & $27369(1.2)$ & 84 \\
\hline
\end{tabular}

\#Geometric means and S.D. 
with greater suppressibility following dexamethasone have been reported in some populations of men and women $(11,12)$.

To our knowledge, gender differences in the association between low birth weight and responsiveness of the HPA axis have not been reported before. Studies by Reynolds et al. showed gender differences in the cortisol responses to HPA manipulation, as did our results, but found no interaction effect of gender and low birth weight on HPA responsiveness $(13,14)$. Animal experiments have shown gender-specific HPA reactions as a consequence of prenatal undernutrition, which points to an increase in adrenal sensitivity in females (8). However, the link between small size at birth and greater suppressibility of the HPA axis in women in our study does not seem to be caused by undernutrition in utero. Size at birth is a summary measure of fetal growth, which only indirectly relates to maternal nutrition. It is a result of a wide range of maternal, placental and fetal factors. It has been shown that size at birth can produce permanent effects on adult health independently from prenatal undernutrition; it has also been found that prenatal undernutrition can have profound effects in the later life without affecting size at birth $(18,33,34)$.

In summary, we found no evidence in support of the hypothesis that prenatal famine exposure programs response to dexamethasone suppression and $\mathrm{ACTH}_{1-24}$ stimulation at the adrenal level of the HPA axis. At the levels of the hippocampus and hypothalamus there may be programming by famine exposure in utero. We are currently testing this assumption by performing psychological stress tests in our cohort.

\section{Acknowledgements}

This study was funded by the Netherlands Heart Foundation (grant number 2001B087), the Academic Medical Center (Amsterdam, The Netherlands) and the Medical Research Council (UK). We thank the participants for their willing cooperation.

\section{References}

1 Barker DJP. Mothers, babies and health in later life. Edinburgh: Churchill Livingstone, 1998.

2 Welberg LA \& Seckl JR. Prenatal stress, glucocorticoids and the programming of the brain. Journal of Neuroendocrinology 200113 $113-128$

3 Rosmond R \& Bjorntorp P. The hypothalamic-pituitary-adrenal axis activity as a predictor of cardiovascular disease, type 2 diabetes and stroke. Journal of Internal Medicine $2000 \mathbf{2 4 7}$ 188-197.

4 Andrews RC, Herlihy O, Livingstone DE, Andrew R \& Walker BR. Abnormal cortisol metabolism and tissue sensitivity to cortisol in patients with glucose intolerance. Journal of Clinical Endocrinology and Metabolism 200287 5587-5593.
5 Lesage J, Blondeau B, Grino M, Breant B \& Dupouy JP. Maternal undernutrition during late gestation induces fetal overexposure to glucocorticoids and intrauterine growth retardation, and disturbs the hypothalamo-pituitary-adrenal axis in the newborn rat. Endocrinology 2001142 1692-1702.

6 Hawkins P, Steyn C, McGarrigle HH, Calder NA, Saito T, Stratford LL, Noakes DE \& Hansona MA. Cardiovascular and hypothalamicpituitary-adrenal axis development in late gestation fetal sheep and young lambs following modest maternal nutrient restriction in early gestation. Reproduction, Fertilily and Development 200012 $443-456$.

7 Bloomfield FH, Oliver MH, Giannoulias CD, Gluckman PD, Harding JE \& Challis JRG. Brief undernutrition in late-gestation sheep programs the hypothalamic-pituitary-adrenal axis in adult offspring. Endocrinology $20031442933-2940$.

8 Lingas RI \& Matthews SG. A short period of maternal nutrient restriction in late gestation modifies pituitary-adrenal function in adult guinea pig offspring. Neuroendocrinology 200173 302-311.

9 Levitt N, Lambert E, Woods D, Hales C, Andrew R \& Seckl J. Impaired glucose tolerance and elevated blood pressure in low birth weight, nonobese, young South African adults: early programming of cortisol axis. Journal of Clinical Endocrinology and Metabolism 200085 4611-4618.

10 Phillips D, Walker B, Reynolds R, Flanagan D, Wood P, Osmond C, Barker DJP \& Whorwood C. Low birth weight predicts elevated plasma cortisol concentrations in adults from 3 populations. Hypertension 200035 1301-1306.

11 Kajantie E, Eriksson J, Barker DJP, Forsen T, Osmond C, Wood PJ, Andersson S, Dunkel L \& Phillips DI. Birthsize, gestational age and adrenal function in adult life: studies of dexamethasone suppression and $\mathrm{ACTH}_{1-24}$ stimulation. European Journal of Endocrinology 2003149 569-575.

12 Ward AMV, Syddall HE, Wood PJ, Chrousos GP \& Phillips DIW. Fetal programming of the hypothalamic-pituitary-adrenal (HPA) axis: low birth weight and central HPA regulation. Journal of Clinical Endocrinology and Metabolism 200489 1227-1233.

13 Reynolds R, Walker B, Syddall H, Andrew R, Wood P, Whorwood C \& Phillips D. Altered control of cortisol secretion in adult men with low birth weight and cardiovascular risk factors. Journal of Clinical Endocrinology and Metabolism 200186 245-250.

14 Reynolds RM, Walker BR, Syddall HE, Andrew R, Wood PJ \& Phillips DI. Is there a gender difference in the associations of birthweight and adult hypothalamic-pituitary-adrenal axis activity? European Journal of Endocrinology 2005152 249-253.

15 Ravelli ACJ, van der Meulen JHP, Michels RPJ, Osmond C, Barker DJP, Hales CN \& Bleker OP. Glucose tolerance in adults after prenatal exposure to famine. Lancet 1998351 173-177.

16 Painter RC, Roseboom TJ, van Montfrans GA, Bossuyt PM, Krediet RT, Osmond C, Barker DJP \& Bleker OP. Microalbuminuria in adults after prenatal exposure to the Dutch famine. Journal of the American Society of Nephrology 200516 189-194.

17 Roseboom TJ, van der Meulen JHP, Osmond C, Barker DJP, Ravelli ACJ, Tanka JS, van Montfrans GA, Michels RPJ \& Bleker OP. Coronary heart disease after prenatal exposure to the Dutch famine, 1944-45. Heart $2000 \mathbf{8 4}$ 595-598.

18 Roseboom TJ, van der Meulen JHP, Osmond C, Barker DJP, Ravelli ACJ \& Bleker OP. Plasma lipid profiles in adults after prenatal exposure to the Dutch famine. American Journal of Clinical Nutrition 200072 1101-1106.

19 Roseboom TJ, van der Meulen JHP, Ravelli ACJ, Osmond C, Barker DJP \& Bleker OP. Plasma fibrinogen and factor VII concentrations in adults after prenatal exposure to famine. British Journal of Haematology 2000111 112-117.

20 Ravelli ACJ, van der Meulen JHP, Osmond C, Barker DJP \& Bleker OP. Obesity at the age of $50 \mathrm{y}$ in men and women exposed to famine prenatally. American Journal of Clinical Nutrition 199970 $811-816$.

21 Roseboom TJ, Van Der Meulen JHP, Ravelli ACJ, Osmond C, Barker DJP \& Bleker OP. Perceived health of adults after prenatal exposure to the Dutch famine. Paediatric and Perinatal Epidemiology 200317 391-397. 
22 Trienekens G. Tussen ons volk en de honger, p. 535. Utrecht: Matrijs, 1985

23 de Rooij SR, Painter RC, Roseboom TJ, Phillips DIW, Osmond O, Barker DJP, Tanck MW, Michels RPJ, Bossuyt PMM \& Bleker OP. Glucose tolerance at age 58 and the decline of glucose tolerance in comparison with age 50 in people prenatally exposed to the Dutch famine famine. Diabetologia 200649 637-643.

24 World Health Organization. Definition, diagnosis and classification of diabetes mellitus and its complications. Report of a WHO consultation, Part 1, diagnosis and classification. Geneva: World Health Organization, 1999.

25 Bakker B \& Sieben I. Maten voor prestige, sociaal-economische status en sociale klasse voor de standaard beroepenclassificatie 1992. Sociale Wetenschappen 199740 1-22.

26 Executive Summary of The Third Report of The National Cholesterol Education Program (NCEP). Expert Panel on Detection, Evaluation, And Treatment of High Blood Cholesterol In Adults (Adult Treatment Panel III). Journal of the American Medical Association 2001285 2486-2497.

27 Grundy SM, Hansen B, Smith SC Jr, Cleeman JI \& Kahn RA. Clinical management of metabolic syndrome: report of the American Heart Association/National Heart, Lung, and Blood Institute/American Diabetes Association conference on scientific issues related to management. Circulation 2004109 551-556.

28 Sebaai N, Lesage J, Breton C, Vieau D \& Deloof S. Perinatal food deprivation induces marked alterations of the hypothalamopituitary-adrenal axis in 8-month-old male rats both under basal conditions and after a dehydration period. Neuroendocrinology 200479 163-173.
29 Kirschbaum C, Pirke KM \& Hellhammer DH. The 'Trier Social Stress Test' - a tool for investigating psychobiological stress responses in a laboratory setting. Neuropsychobiology $1993 \mathbf{2 8}$ 76-81.

30 Liu L, Li A \& Matthews SG. Maternal glucocorticoid treatment programs HPA regulation in adult offspring: sex-specific effects. American Journal of Physiology, Endocrinology and Metabolism 2001 280 E729-E739.

31 Banjanin S, Kapoor A \& Matthews SG. Prenatal glucocorticoid exposure alters hypothalamic-pituitary-adrenal function and blood pressure in mature male guinea pigs. Journal of Physiology 2004558 305-318.

32 Phillips DI, Bennett FI, Wilks R, Thame M, Boyne M, Osmond C \& Forrester TE. Maternal body composition, offspring blood pressure and the hypothalamic-pituitary-adrenal axis. Paediatric and Perinatal Epidemiology $200519294-302$.

33 Roseboom TJ, van der Meulen JHP, Ravelli ACJ, Montfrans GA, Osmond C, Barker DJP \& Bleker OP. Prenatal exposure to the Dutch famine and health in later life. Journal of Hypertension 199917 325-330.

34 Harding JE. The nutritional basis of the fetal origins of adult disease. International Journal of Epidemiology 200130 15-23.

Received 9 March 2006

Accepted 28 April 2006 